
About IJMA [last updated July, $\left.1^{\text {st }}, 2021\right]$

$\checkmark$ International Journal of Medical Arts is the Official Journal of the Damietta Faculty of Medicine, AlAzhar University, Egypt

$\checkmark$ It is an International, Open Access, Double-blind, Peer-reviewed Journal

$\checkmark$ Published four times a year

$\checkmark$ The First Issue was published in July 2019

$\checkmark$ Published under the following license: Creative Commons Attribution-ShareAlike 4.0 International Public License (CC BY-SA 4.0). It had updated from the Creative Commons license [CC BY] in volume 2, Issue 4, October 2020 About IJMA

$\checkmark$ The Egyptian Knowledge Bank hosts the web site of IJMA

$\checkmark$ The Egyptian Knowledge Bank supports IJMA

$\checkmark$ IJMA follows the regulations of the International Committee of Medical Journal Editors

$\checkmark$ IJMA is indexed in the "Directory of Open Access Journals" [15 January 2021].

$\checkmark$ IJMA is indexed in JGate [29-6-2021]

$\checkmark$ IJMA is a member of the International Society of Managing and Technical Editors

$\checkmark$ Listed in "Index Copernicus", "Publons", "Academic resource index [ResearchBib]", "Electronics journal library", "Eurasian Scientific Journal Index", and "Citefactor"

$\checkmark$ IJMA introduced to the search engine [BASE] through DOAJ
Click image to reach the page

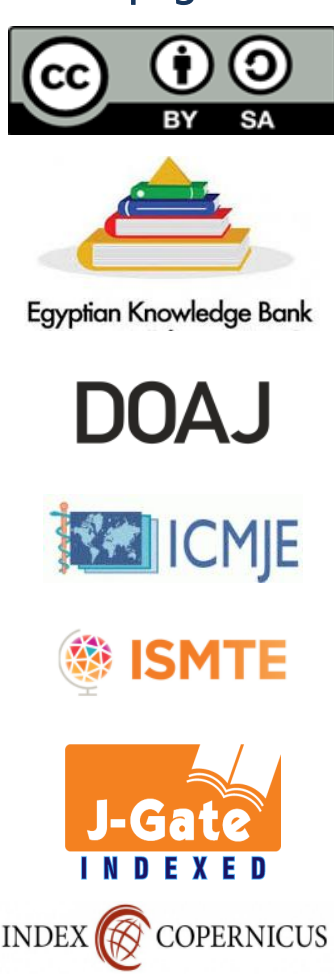

publons

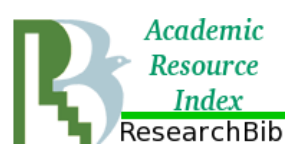

\section{EZ3 \\ .}

ESJII

CiteFactor

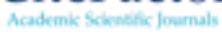

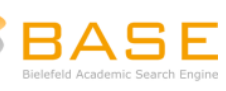




Available online at Journal Website
https://ijma.journals.ekb.eg/
Main subject [Dermatology and Venereology]

Case Report

\title{
Oral Isotretinoin in The Treatment of Recalcitrant Molluscum Contagiosum in Children
}

\author{
Rahma Ramdan [1]; Hany Abou Alwafa [2]; Emad Eldin Elgamal [2].
}

${ }^{1}$ Department of Dermatology, Venereology and Andrology, Dermatology and Leprosy Hospital in Damietta, Ministry of Health, Egypt.

2 Department of Dermatology, Venereology and Andrology, Al-Azhar Faculty of Medicine, Damietta, Egypt.

Corresponding author: Rahma Ramdan

Email: rahma_ramdan2020@yahoo.com

Submission date: April 05, 2021; Revision date: May 31, 2021; Acceptance date: May 31, 2021.

DOI: 10.21608/IJMA.2021.71160.1293

DOAJ

\section{ABSTRACT}

Background: Recalcitrant molluscum contagiosum in children has been treated with many destructive procedures with a high recurrence rate, alternative treatments would be desirable in pediatric patients. Oral isotretinoin has been used to treat viral warts successfully in children.

Aim of the work: Our aim in this study was to investigate the influence of oral isotretinoin in MC patients.

Methods: Twenty children less than 18 years, with recalcitrant molluscum contagiosum were enrolled in this study, the treatment protocol was oral isotretinoin $[0.5 \mathrm{mg} / \mathrm{kg}$ ] daily until complete clearance [maximum duration 3 months]. Patients were evaluated clinically and photographically every two weeks to assess the response to treatment and to report side effects of therapy. Patients with complete response were followed up monthly for three months to record the recurrence rate. Lipid profile [Triglycerides, cholesterol, LDL and HDL] and liver function tests [SGOT and SGPT] were performed before treatment and every 4 weeks during the treatment period.

Results: Mean age of participants was $12.90 \pm 2.64$ years, $80 \%$ of them were more than 10 years old, [65\%] were male, and the mean weight of studied cases was $49.10 \pm 15.33 \mathrm{~kg}$. The face was most common affected site in most cases [45\%]. The mean lesion size was $2.63 \pm 1.11 \mathrm{~mm}$, and mean number of molluscum lesions of $23.55 \pm 12.85$. As regarding to recurrence rate, $93.8 \%$ of cases who had complete response were still free at the end of 3 months follow up and only $6.3 \%$ had recurrence. Reported side effects were dry lips in all participants, $55 \%$ had a dry skin and $30 \%$ had a dry nose.

Conclusion: Oral isotretinoin therapy improves recalcitrant MC lesions in children, which may contribute to its therapeutic efficacy.

Keywords: Isotretinoin; Molluscum Contagiosum; Children; Recalcitrant.

This is an open-access article registered under the Creative Commons, ShareAlike 4.0 International license [CC BY-SA 4.0] [https://creativecommons.org/licenses/by-sa/4.0/legalcode.

Citation: Ramdan R, Abou Alwafa H, Elgamal EE. Oral Isotretinoin in the Treatment of Recalcitrant Molluscum Contagiosum in Children. IJMA 2021; 3 [3] July-September: 1598-1601 [DOI: 10.21608/IJMA.2021.71160.1293].

${ }^{*}$ Main subject and any subcategories have been classified according to the research topic. 


\section{INTRODUCTION}

Molluscum contagiosum [MC] is one of the challenging infectious dermatoses affecting pediatric population. It is caused by molluscum contagiosum virus [MCV], transmitted mainly by direct contact, which can be sexual, non-sexual, or autoinoculation. MC usually presents as firm-adjusted papules, pink or skin-colored, with a glossy and umbilicated surface, multiple lesions usually encountered in immunesuppressed people. Treatment options include, curettage, cryo-therapy, cantharidin, imiquimod, podophyllin, potassium hydroxide, salicylic acid, topical retinoids, oral cimetidine, pulsed dye lasers, silver nitrate and others. However, the efficacy of these treatment options may be unsatisfactory in extensive lesions ${ }^{[1]}$.

Low dose isotretinoin was used in patients with recalcitrant viral warts and showed impressive therapeutic response with low recurrence rate compared to conventional therapies $[2,3]$. The antiproliferative effects of oral retinoids may play a part within the treatment of HPV, changes in keratinocyte differentiation, antiviral activity [down regulate viral replication], also antiangiogenic properties through a lessening of vascular endothelial growth factor [VEGF] release from keratinocytes [2,4].

\section{AIM OF THE WORK}

Our aim in this study was to investigate the influence of oral isotretinoin in MC patients.

\section{PATIENTS AND METHODS}

Twenty children with recalcitrant molluscum contagiosum were enrolled in this study, they were recruited from the outpatient clinic of the Department of Dermatology and Venereology, Al-Azhar University Hospital [Damietta]. The study was approved by Local Ethics Committee; informed consent was obtained from all parents. Patients less than 18 years with multiple or extensive molluscum lesions, recurrent and resistant to other forms of treatment were included. Patients suffering from renal, hepatic, cardiac, or any other systemic diseases, and on any other treatment in the last 3 months were excluded.

Our treatment protocol was oral isotretinoin $[0.5 \mathrm{mg} / \mathrm{kg} /$ day] until complete clearance [maximum duration 3 months], Patients were evaluated clinically and photographically every two weeks to assess the response to treatment and to report side effects of therapy. Patient was instructed to use emollient as needed to reduce skin dryness. Lipid profile [Triglycerides, cholesterol, LDL and HDL], liver function tests [SGOT and SGPT] and complete blood picture was performed before treatment and every 4 weeks during the treatment period.

\section{Assessment of response}

The response was evaluated as: 1. Complete response: complete disappearance of lesions. 2. Partial response: > 50\% improvement. 3. No response: no improvement or $<50 \%$ improvement. Patients with complete response were followed up monthly for three months to record the recurrence rate.

\section{RESULTS}

Our study included 20 children with MC, their mean age was $12.90 \pm 2.64$ years, $80 \%$ of them were more than 10 years old, the majority were male [65\%], and the mean weight of study cases was $49.10 \pm 15.33 \mathrm{~kg} .60 \%$ of cases being studied had no family history of similar condition and all of them had not associated with other systemic comorbidities, $5 \%$ had history of having wart, acne vulgaris. while $10 \%$ had $p$. alba, atopic dermatitis.

According to the distribution, The face was affected in most cases [45\%], [20\%] distributed all over the face, [5\%] around eyes, forehead, chin, and around ear, [10\%] in the neck and trunk, [5\%] distributed in arm \& forearm, arm, axillary area, back of the thigh, cubital fossa, face $\&$ neck, lower back \& buttock and popliteal fossa.

The mean lesion size was $2.63 \pm 1.11 \mathrm{~mm}$, and mean number of molluscum lesion of $23.55 \pm 12.85$. With regard to previous treatments, $25 \%$ of them received topical treatments, $10 \%$ treated by cryotherapy and $5 \%$ had either syringe extraction \& cryotherapy, or syringe extraction or electrocautery. Duration ranges from 8 months to 18 months with relapsing course or partial remission \& exacerbation.

According to investigations following isotretinoin therapy, there was a significant increase in SGOT, SGPT, and cholesterol levels After 1 month of treatment than baseline $[p<0.001$ for all]. HDL significantly decreased After 1 month of treatment than baseline $[p<0.001]$ Table [1].

According to duration of isotretinoin treatment, $60 \%$ of participants received treatment more than 5 weeks with a mean duration of therapy were $6.60 \pm 2.60$ weeks. Reported side effects were dry lips in all participants, $55 \%$ had dry skin and $30 \%$ had dry nose.

Regarding recurrence rate, $93.8 \%$ of cases who had complete response were still free at the end of 3 months follow up and only $6.3 \%$ had recurrence [Table 2 , figure 1 , 2, 3 and 4]. 
Table [1]: Comparison between the two study periods according to investigations.

\begin{tabular}{|c|c|c|c|c|c|}
\hline & Investigations & At base line & After one month & $t$ & $p$ \\
\hline \multirow{3}{*}{ SGOT [U/L] } & Min. - Max. & $14.0-23.0$ & $16.0-34.0$ & \multirow{3}{*}{$5.160^{*}$} & \multirow{3}{*}{$<0.001$} \\
\hline & Mean \pm SD. & $17.95 \pm 2.52$ & $22.60 \pm 4.75$ & & \\
\hline & Median [IQR] & $18.0[16.0-20.0]$ & $22.0[19.0-26.0]$ & & \\
\hline \multirow{3}{*}{ SGPT [U/L] } & Min. - Max. & $14.0-22.0$ & $17.0-28.0$ & \multirow{3}{*}{$8.018^{*}$} & \multirow{3}{*}{$<0.001$} \\
\hline & Mean \pm SD. & $17.70 \pm 2.45$ & $21.75 \pm 3.40$ & & \\
\hline & Median [IQR] & $17.50[16.0-19.50]$ & $20.50[19.0-24.0]$ & & \\
\hline \multirow{3}{*}{ CHOL [mg/dl] } & Min. - Max. & $107.0-157.0$ & $117.0-174.0$ & \multirow{3}{*}{$5.125^{\star}$} & \multirow{3}{*}{$<0.001^{*}$} \\
\hline & Mean \pm SD. & $136.1 \pm 15.87$ & $145.4 \pm 17.37$ & & \\
\hline & Median [IQR] & $139.5[120.5-148.0]$ & $147.5[132.0-158.0]$ & & \\
\hline \multirow{3}{*}{ TG [mg/dl] } & Min. - Max. & $46.0-79.0$ & $55.0-87.0$ & \multirow{3}{*}{$8.614^{*}$} & \multirow{3}{*}{$<0.001^{*}$} \\
\hline & Mean \pm SD. & $62.35 \pm 9.95$ & $70.95 \pm 9.56$ & & \\
\hline & Median [IQR] & $60.0[55.0-69.0]$ & $71.50[63.50-78.0]$ & & \\
\hline \multirow{3}{*}{ LDL [mg/dl] } & Min. - Max. & $62.60-100.3$ & $8.20-111.6$ & \multirow{3}{*}{1.948} & \multirow{3}{*}{0.066} \\
\hline & Mean \pm SD. & $77.68 \pm 11.49$ & $85.10 \pm 21.21$ & & \\
\hline & Median [IQR] & $75.20[68.75-86.0]$ & $89.50[77.0-98.0]$ & & \\
\hline \multirow{3}{*}{$\mathrm{HDL}[\mathrm{mg} / \mathrm{dl}]$} & Min. - Max. & $35.0-54.0$ & $31.0-51.0$ & \multirow{3}{*}{$4.781^{*}$} & \multirow{3}{*}{$<0.001^{\prime}$} \\
\hline & Mean \pm SD. & $46.10 \pm 5.27$ & $40.70 \pm 6.01$ & & \\
\hline & Median [IQR] & $47.50[42.50-49.50]$ & $40.0[36.50-45.50]$ & & \\
\hline
\end{tabular}

t: Paired t-test; $p$ : $p$ value for comparing between the period being studied; *: Statistically significant at $p \leq 0.05$

Table [2]: Distribution of the cases being studied according to results.

\begin{tabular}{|c|c|c|c|}
\hline & Results & No. & $\%$ \\
\hline \multirow[t]{3}{*}{ Size } & No change & 1 & 5.0 \\
\hline & A slight decrease & 1 & 5.0 \\
\hline & Decrease & 18 & 90.0 \\
\hline \multirow[t]{3}{*}{ Number } & No change & 1 & 5.0 \\
\hline & A slight decrease & 1 & 5.0 \\
\hline & Decrease & 18 & 90.0 \\
\hline \multirow[t]{3}{*}{ Remission degree } & No response & 1 & 5.0 \\
\hline & Complete & 16 & 80.0 \\
\hline & Partial response & 3 & 15.0 \\
\hline
\end{tabular}

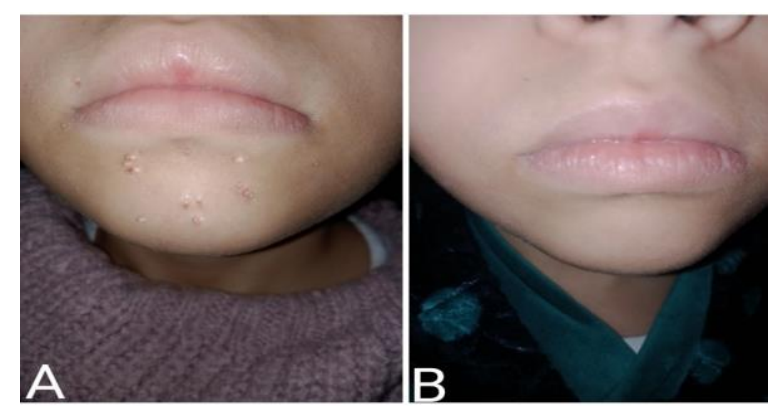

Figure [1]: Eleven years old female with multiple MC around the mouth for 9 months duration before treatment. [B] The same patient after treatment and 3 months follows up.

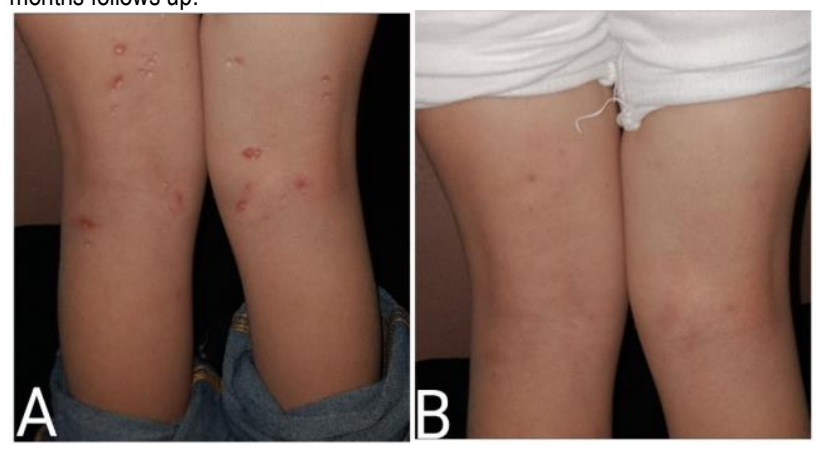

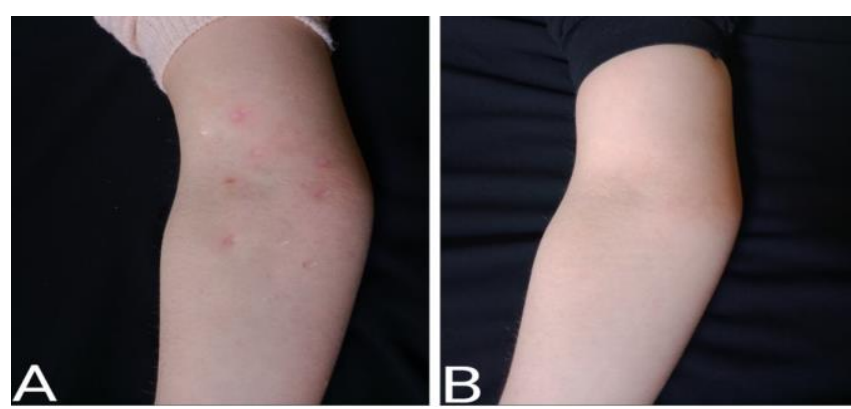

Figure [2]: [A] Twelve years old female with multiple $M C$ in cubital fossa for 8 month duration before treatment. $[B]$ The same patient after treatment and 3 months follows up.

Figure [3]: $[\mathrm{A}]$ Thirteen years old male with multiple MC in popliteal fossa for 11 months duration before treatment. $[\mathrm{B}]$ The same patient after treatment and 3 months follows up. 
DISCUSSION

Several studies proved the efficacy of oral isotretinoin in treating viral warts either plane warts, common warts or condyloma acuminate. We assumed that the same mechanism of action could work to treat molluscum contagiosum as well. There is no standardized therapeutic approach to treat MC, clinicians usually use multiple destructive, topical and systemic therapies, although MC lesions might resolve spontaneously.

Our hypothesis was that oral isotretinoin could be an alternative systemic therapy to treat pediatric cases of recalcitrant MC. A significant clinical response was obtained in our study regarding size and number of MC lesions, which has been decreased significantly after oral isotretinoin therapy. No need for painful destructive procedures, or repeated applications of topical therapy that are messy, especially in multiple MC. Many studies reported that cryotherapy is as an effective treatment modality for MC, but it's painful in children and post-inflammatory pigmentary changes usually occur ${ }^{[5]}$.

Curettage can be frightening for young children usually only performed on older children, teens ${ }^{[6]}$. Many studies proved that topical Imiquimod $5 \%$ cream is a useful treatment option for $M C$ in children 7,8 is capable of stimulating the innate cutaneous immunity, potent anti-viral and immunomodulatory effects, side effects were mild to moderate irritation [9]. Topical tretinoin cream $0.05 \%$ has been compared to $5 \% \mathrm{KOH}$ solution in treating $\mathrm{MC}$, both shown to be effective especially in children when applied for 4 weeks ${ }^{[10] .}$

To our knowledge, the present study is the first that assesses the efficacy of oral isotretinoin to treat recalcitrant molluscum contagiosum. We concluded that oral isotretinoin [0.5 mg/kg daily] in 4-6 weeks [maximum duration 3 months] is efficient in managing recalcitrant $\mathrm{MC}$ in children. Side effects reported in our study were dryness in skin and mucus membranes, which were manageable in most patients, they were dose-duration dependent.

Limitations of the study include the lack of a control group, small number of recruited cases, and lack of comparison between isotretinoin and other therapeutic modalities. Also, monthly blood tests may be frightening to children, and sever dryness of skin and mucous membranes which may occur is painful and can't tolerated especially with atopic dermatitis. Nevertheless, we believe that placebo-controlled studies with greater sample sizes are needed.
Financial and Non-financial Relationships and Activities of Interest

None

\section{REFERENCES}

1. Meza-Romero R, Navarrete-Dechent C, Downey C. Molluscum contagiosum: an update and review of new perspectives in etiology, diagnosis, and treatment. Clin Cosmet Investig Dermatol. 2019 May 30; 12:373-381. [DOI: 10.2147/CCID.S187224].

2. Dave $D D$, Abdelmaksoud A. Low dose isotretinoin as an adjuvant therapy for treatment of different clinical variants of warts: A case series. Dermatol Ther. 2019 Mar;32 [2]: e12836. [DOI: 10.1111/dth.12836].

3. Al-Hamamy HR, Salman HA, Abdulsattar NA. Treatment of plane warts with a low-dose oral isotretinoin. ISRN Dermatol. 2012; 2012:163929. [DOI: 10.5402/2012/ 163929].

4. Georgala S, Katoulis AC, Georgala C, Bozi E, Mortakis A. Oral isotretinoin in the treatment of recalcitrant condylomata acuminata of the cervix: a randomised placebo-controlled trial. Sex Transm Infect. 2004 Jun; 80 [3]: 216-8. [DOI: 10.1136/sti.2003.006841].

5. Handjani F, Behazin E, Sadati MS. Comparison of $10 \%$ potassium hydroxide solution versus cryotherapy in the treatment of molluscum contagiosum: an open randomized clinical trial. J Dermatolog Treat. 2014 Jun;25[3]:249-50. [DOI: 10.3109/09546634.2013.832135].

6. Del Rosso JQ, Kircik L. Topical Cantharidin in the Management of Molluscum Contagiosum: Preliminary Assessment of an Ether-free, Pharmaceutical-grade Formulation. J Clin Aesthet Dermatol. 2019 Feb;12[2]:27-30. [PMID: 30881580].

7. Bayerl C, Feller G, Goerdt S. Experience in treating molluscum contagiosum in children with imiquimod $5 \%$ cream. Br J Dermatol. 2003 Nov;149 Suppl 66:25-9. [DOI: 10.1046/j.0366-077x.2003. 05631.x].

8. Arican O. Topical treatment of molluscum contagiosum with imiquimod 5\% cream in Turkish children. Pediatr Int. 2006 Aug; 48 [4]: 403-5. [DOI: 10.1111/j.1442-200X.2006. 02229.x].

9. Badavanis G, Pasmatzi E, Monastirli A, Georgiou S, Tsambaos D. Topical Imiquimod is an Effective and Safe Drug for Molluscum Contagiosum in Children. Acta Dermatovenerol Croat. 2017 Jul;25[2]:164-166. [PMID: 28871935.

10. Rajouria EA, Amatya A, Karn D. Comparative study of $5 \%$ potassium hydroxide solution versus $0.05 \%$ tretinoin cream for Molluscum Contagiosum in children. Kathmandu Univ Med J [KUMJ]. 2011 OctDec;9[36]:291-4. [DOI: 10.3126/ kumj. v9i4.6347. 

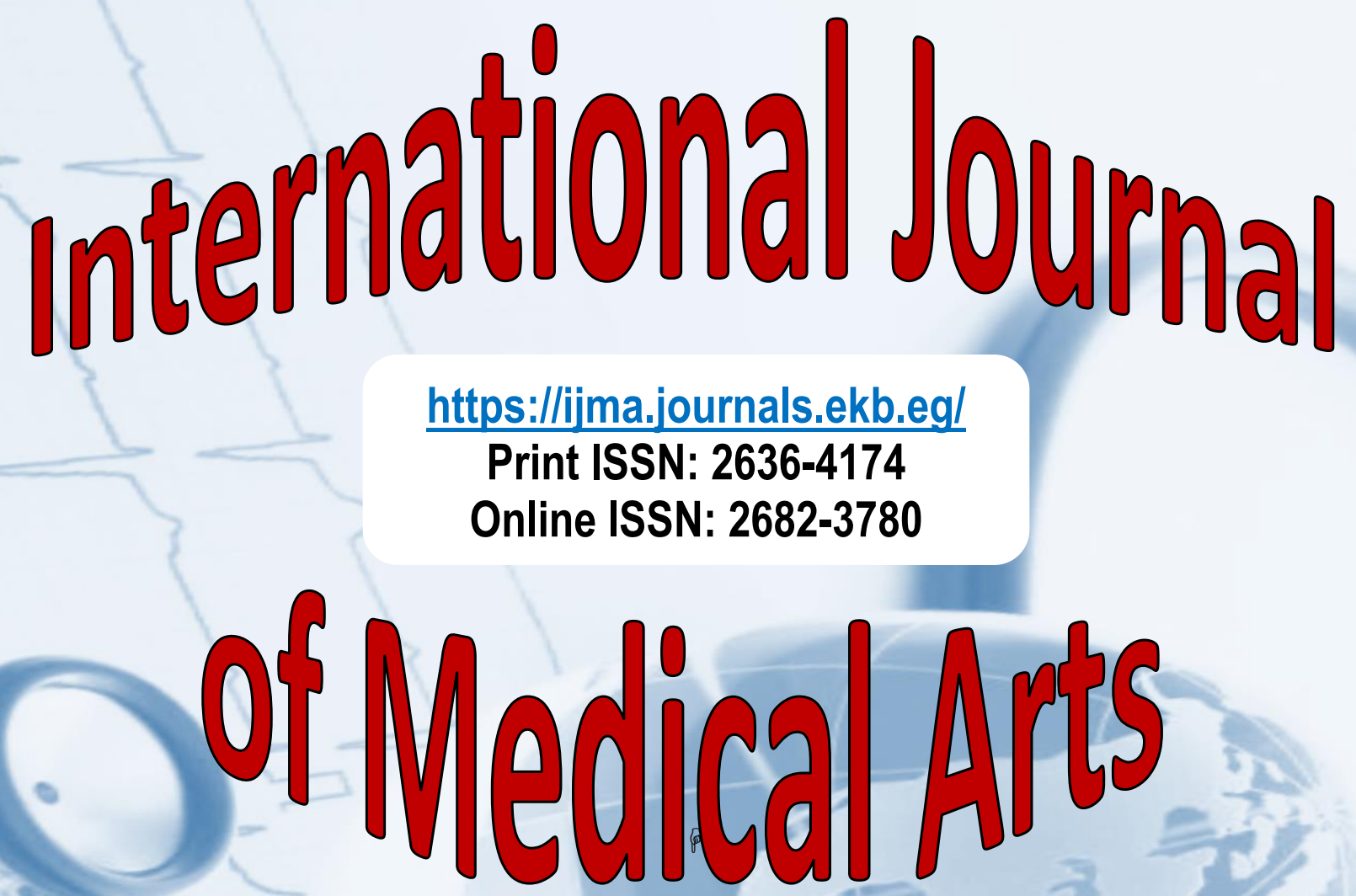